\title{
Diversity in regulation of adhesion molecules (Mac-1 and L-selectin) in monocytes and neutrophils from neonates and adults
}

\author{
C Török, J Lundahl, J Hed, H Lagercrantz
}

\begin{abstract}
The surface expression and regulation of the adhesion promoting glycoproteins Mac-1 and L-selectin was measured on monocytes and neutrophils from neonates and adults. A significant decrease in Mac-1 up regulation on both monocytes and neutrophils was found in neonates after both high $\left(10^{-7} \mathrm{M}\right)$ and low $\left(10^{-9} \mathrm{M}\right)$ concentrations of the chemotactic factor $N$-formyl-methionyl-phenylalanine (FMLP). A significant difference was obtained after incubation for five minutes, which was further enhanced after incubation for 15 minutes. Factors related to bacterial infections, lipopolysaccharides, activated sera (C5a), and aggregated IgG induced an impaired Mac-1 up regulation on both monocytes and neutrophils from neonates compared with adults. The expression of L-selectin was significantly lower on neutrophils from neonates and was less down regulated upon stimulation with a low concentration $\left(10^{-12} \mathrm{M}\right)$ of FMLP. On monocytes from neonates, the expression and down regulation of $L$ selectin did not differ from monocytes from adults. Mode of delivery did not influence the regulation of Mac-1 and Lselectin in neonates.

Diversity in expression and regulation of Mac-1 and L-selectin on monocytes and neutrophils may contribute to the increased susceptibility to infections observed in neonates.

(Arch Dis Child 1993; 68: 561-565)
\end{abstract}

The immunological host defence is immature in the human neonate, which may contribute to the high incidence of overwhelming sepsis in preterm and term infants. ${ }^{1}$ The most consistent defect described is the inability of the neonatal neutrophils to accumulate at the site of bacterial invasion. ${ }^{2}$ This is partly due to a reduced neutrophil storage pool and a failure to increase the stem cell proliferation rate during sepsis. ${ }^{3} 4$ Previous studies have revealed that neutrophils from neonates have impaired adherence to and migration through endothelium and also impaired chemotaxis. ${ }^{5-8}$ Immaturity in other defence systems ${ }^{9}$ such as decreased opsonic activity ${ }^{9} 10$ can contribute to the increased infection rate. During acute inflammation, neutrophils and monocytes are recruited to the inflammatory site. ${ }^{11-13}$ Neutrophils are important effector cells during bacterial infections and monocytes undergo maturation to inflammatory macrophages performing both immune and non-immune functions. ${ }^{13} 14$

Both neutrophils and monocytes pass several transient attachments to the vessel walls before the final adhesion to and transmigration through the endothelium. ${ }^{15-17}$ This recruitment is regulated by a sequential interaction of different adhesion molecules. Two important families of adhesion molecules are involved in this recruitment and are designated selectins and integrins. Selectins mediate the first step of attachment to endothelium; this is called 'rolling'. ${ }^{18-20}$ This rolling preceeds a firm adhesion that is mediated by the integrin family. ${ }^{15} 16$ L-Selectin is distributed on most leucocytes and is down regulated upon stimulation with chemotactic factors. ${ }^{21} 22$ Mac-1 is an important adhesion molecule in the integrin family that mediates firm adhesion to endothelium. Upon stimulation with chemotactic factors, Mac-1 is rapidly mobilised to the surface from an intracellular pool. ${ }^{23-25}$ This inverse regulation of L-selectin and Mac-1 is a prerequisite for the sequential interaction between inflammatory cells and endothelium leading to an inflammatory response.

The aim of the present study was to see whether immaturity of expression and regulation of these adhesion molecules on monocytes and neutrophils could predispose to severe infection in the infant.

\section{Methods}

BLOOD SAMPLES

Blood was collected from the placental side of the umbilical cord immediately after uncomplicated vagina deliveries $(n=19)$ and caesarean section $(n=6)$. All infants were full term (37-42 weeks) with a mean birth weight of $3600 \mathrm{~g}$; girls/boys 16/9; and average Apgar scores were $9,10,10$ at 1,5 , and 10 minutes respectively. For the control samples, blood was collected from healthy non-allergic blood donors aged between 18 and 65 years.

All samples were collected in ethylenediaminetetra-acetic acid (EDTA) tubes and were analysed within four hours.

\section{LEUCOCYTE PREPARATION}

EDTA blood was haemolysed in $50 \mu$ l aliquots by dilution in $2 \mathrm{ml}$ cold ammonium chlorideEDTA 'lysing reagent' (Ortho Diagnostic Systems) for five minutes at $15^{\circ} \mathrm{C}$ followed by centifugation for five minutes at $300 \mathrm{~g}$ at $4^{\circ} \mathrm{C}$. The leucocyte pellets were washed once in
J Hed

Correspondence to Dr Lundahl.

Accepted 14 December 1992
Karolinska Hospital of Paediatrics

Department of Clinical Immunology 
$0 \cdot 15 \mathrm{M}$ cold phosphate buffered saline supplemented with $0.1 \mathrm{mM}$ EDTA and $0.02 \%$ sodium azide (PBS-EDTA) and were then resuspended in Roswell Park Memorial Institute (RPMI) 1640 medium (Northumbria Biologicals Ltd).

\section{VIABILITY TESTING}

Viability testing was performed by incubating leucocyte pellets with carboxyfluorescein diacetate (CFDA) $(10 \mu \mathrm{g} / \mathrm{ml})$ (Becton and Dickinson Immunocytometry Systems) for 15 minutes at $18^{\circ} \mathrm{C}$ followed by one wash in PBSEDTA at $4^{\circ} \mathrm{C}$. CFDA was retained and hydrolysed by intracellular esterases, yielding green fluoresceins. The fluorescence intensity was analysed with flow cytometry (see below) and results are expressed as percent CFDA positive cells.

REAGENTS FOR RECEPTOR MOBILISATION

Lipopolysaccharides prepared from Escherichia coli 026:B6 was used at a concentration of 100 $\mu \mathrm{g} / \mathrm{ml}$. As the effect of lipopolysaccharides on Mac-1 mobilisation is enhanced in the presence of lipopolysaccharide binding protein, ${ }^{26} \mathrm{RPMI}$ was supplemented with $10 \%$ heat inactivated normal human sera from healthy $A B R h+$ blood donors. $\quad N$-formyl-methionyl-phenylalanine (FMLP) was diluted to different concentrations from a $10^{-3} \mathrm{M}$ pool stored at $-70^{\circ} \mathrm{C}$. Lipopolysaccharides and FMLP were purchased from Sigma Chemical. Aggregated IgG was prepared from Gammaglobulin Kabi $165 \mathrm{mg} / \mathrm{ml}$ (Kabi Vitrum). The gammaglobulin was diluted to $20 \mathrm{mg} / \mathrm{ml}$ in RPMI medium and incubated at $63^{\circ} \mathrm{C}$ for 30 minutes. After incubation the gammaglobulin was diluted to a final concentration of $2.5 \mathrm{mg} / \mathrm{ml}$. Sera from healthy $\mathrm{AB} \mathrm{Rh}+$ blood donor was incubated with heat killed yeast particles to obtain complement activation products, which major chemoattractant is generally considered to be C5a des arg. This sera was then diluted in RPMI medium to a final concentration of $10 \%$ and was designated normal human serum in this study.

IMMUNOSTAINING AND FLOW CYTOMETRY

Mac-1 and L-selectin expression on leucocytes was analysed by adding $10 \mu \mathrm{l}$ of phycoerythrinconjugated monoclonal anti-CD16 and $10 \mu \mathrm{l}$ FITC-conjugated anti-Leu 8 respectively (Becton and Dickinson Immunocytometry Systems) to the leucocyte pellets prepared as described above. The suspensions were incubated on ice for 30 minutes and then washed twice in cold PBS-EDTA. Isotype matched

Unstimulated (kept at $4^{\circ} \mathrm{C}$ ) leucocytes from neonates and adults analysed according to surface expression of Mac-1 and L-selectin. Results (mean fluorescense intensity) are expressed as mean (SD)

\begin{tabular}{|c|c|c|c|c|}
\hline & \multicolumn{2}{|l|}{$M a c-1$} & \multicolumn{2}{|l|}{ L-Selectin } \\
\hline & $\begin{array}{l}\text { Neonates } \\
(n=20)\end{array}$ & $\begin{array}{l}\text { Adults } \\
(n=20)\end{array}$ & $\begin{array}{l}\text { Neonates } \\
(n=9)\end{array}$ & $\begin{array}{l}\text { Adults } \\
(n=10)\end{array}$ \\
\hline $\begin{array}{l}\text { Monocytes } \\
\text { Neutrophils }\end{array}$ & $\begin{array}{l}13.7(6.3) \\
14.9(6.9)\end{array}$ & $\begin{array}{l}20 \cdot 6(9 \cdot 8)^{\star} \\
12 \cdot 9(7 \cdot 1)\end{array}$ & $\begin{array}{l}29 \cdot 1(8 \cdot 6) \\
23 \cdot 0(6 \cdot 0)\end{array}$ & $\begin{array}{l}31 \cdot 0(9 \cdot 9) \\
38 \cdot 4(4 \cdot 2)^{\star \star}\end{array}$ \\
\hline
\end{tabular}

control antibodies, phycoerythrin-conjugated $\mathrm{IgG}_{2}$ and fluorescein isothiocyanate (FITC)conjugated $\mathrm{IgG}_{2}$ (Becton and Dickinson Immunocytometry Systems) were used to define the cut off for positive fluorescence, which was the 99 th centile of the distribution of the cells labelled with control antibody. The cells were finally resuspended in $0.5 \mathrm{ml}$ PBS-EDTA and analysed in Epics Profile 1 (Coulter Inc). Based on light scattering properties, each cell is represented by a point in a rectangular coordinate system. Discrimination frames were placed around the granulocyte and monocyte clusters. In control experiments the purity of neutrophils and monocytes within the respective cluster were defined with CD16 monoclonal antibody (Becton and Dickinson Immunocytometry Systems) and CD14 monoclonal antibody (Coulter Inc), respectively. The instrument gives the mean fluorescence intensity of the cell population within each discrimination frame.

STATISTICAL ANALYSIS

Results are expressed as mean (SD). Differences between groups were analysed using non-parametric method (Mann-Whitney $U$ test) and were considered statistically significant at $\mathrm{p}<0 \cdot 05$.

\section{Results}

VIABILITY AND CELL PURITY

The viability, measured as percentage CFDA positive cells, was $>97 \%$ for both granulocytes (neonates $99.1(0.90 \%$, adults $98.6(0.9) \%)$ and for monocytes (neonates $97 \cdot 3(1.2) \%$, adults $98.8(0.9) \%)$. The purity of neutrophils and monocytes in respective clusters was measured with anti-CD16 and anti-CD14 respectively. CD16 positive cells were $97.5(0 \cdot 7) \%$ for neonates and $96.7(1 \cdot 0) \%$ for adults. CD14 positive cells were $95 \cdot 1(2 \cdot 2) \%$ for neonates and $93.9(1.3) \%$ for adults.

\section{EXPRESSION OF MAC-1 AND L-SELECTIN ON UNSTIMULATED NEUTROPHILS AND MONOCYTES}

The surface expression of Mac-1 on unstimulated (kept at $4^{\circ} \mathrm{C}$ ) monocytes was lower in neonates compared with adults $(13.7(6 \cdot 3)$ and $20.6(9.8)$ mean fluorescence intensity respectively, $p<0.05)$. On neutrophils, the expression was comparable between neonates and adults $(14.9(6.9)$ and $12.9(7 \cdot 1)$ mean fluorescence intensity respectively; (table). The expression of L-selectin was significantly $(\mathrm{p}<0.001)$ lower on neutrophils from neonates compared with adults but was similar on monocytes (table).

EFFECT OF DIFFERENT INCUBATION TIME AND FMLP CONCENTRATIONS ON MAC-1 MOBILISATION ON NEUTROPHILS AND MONOCYTES

Leucocytes were incubated with buffer alone or buffer supplemented with different concentrations of FMLP at $37^{\circ} \mathrm{C}$ for five and 15 

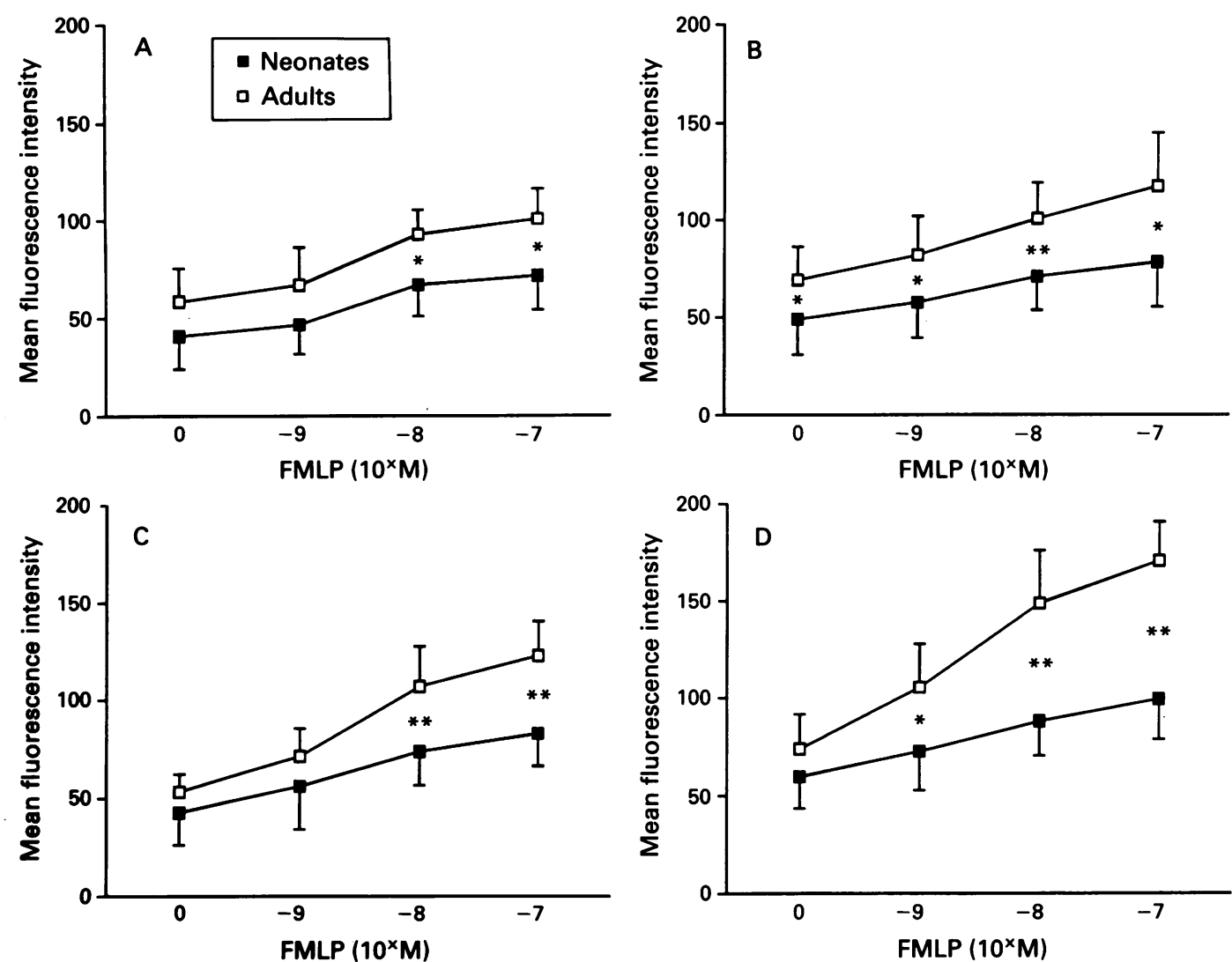

Figure 1 Leucocytes from neonates and adults were incubated with buffer alone or buffer supplemented with different concentrations of FMLP for five $(A)$ and $(C)$ and $15(B)$ and $(D)$ minutes at $37^{\circ} \mathrm{C}$. After incubation the leucocytes were analysed according to Mac-1 surface expression. The monocyte $(A)$ and $(B)$ and neutrophil $(C)$ and $(D)$ population was gated and analysed by flow cytometry. Results are expressed as mean (SD) and are based on seven experiments; ${ }_{*}^{*}=p<0.05, * *=p<0.01$.

minutes to obtain mobilisation of Mac-1. We observed a dose and time related increase in Mac-1 expression on monocytes and neutrophils from neonates and adults. The surface expression of Mac-1 on monocytes from neonates was significantly $(p<0.05)$ lower after five minutes incubation with buffer supplemented with FMLP $\left(10^{-8} \mathrm{M}\right.$ to $10^{-7} \mathrm{M}$ fig $\left.1 \mathrm{~A}\right)$. After 15 minutes incubation, monocytes from neonates expressed significantly $(p<0.05)$ less Mac-1 and also after incubation with buffer alone and buffer supplemented with a low $\left(10^{-9} \mathrm{M}\right)$ concentration of FMLP (fig 1B).

The mobilisation of Mac-1 on neutrophils showed a similar pattern as monocytes with significantly $(p<0.01)$ lower surface expression of Mac-1 on neonatal compared with adult neutrophils after incubation for five minutes with buffer supplemented with FMLP $\left(10^{-8} \mathrm{M}\right.$ to $10^{-7} \mathrm{M}$; fig $1 \mathrm{C}$ ). After 15 minutes incubation, neutrophils from neonates expressed less Mac-1 compared with adult neutrophils after incubation with a broader range of FMLP concentrations $\left(10^{-9} \mathrm{M}-10^{-7} \mathrm{M}\right.$; fig $\left.1 \mathrm{D}\right)$.

THE EFFECT OF LIPOPOLYSACCHARIDES AGGREGATED IgG, AND C5a ON MAC-1 MOBILISATION ON NEUTROPHILS AND MONOCYTES

To evaluate the effect of factors related to bacterial infections, leucocytes were incubated with aggregated IgG $(2.5 \mathrm{mg} / \mathrm{ml})$, normal human serum $(10 \%)$ and lipopolysaccharides (100 $\mu \mathrm{g} / \mathrm{ml})$ at $37^{\circ} \mathrm{C}$ for 15 minutes. All these stimuli caused a significantly $(p<0.01)$ lower Mac-1 surface expression on monocytes (fig $2 \mathrm{~A}$ ) and neutrophils (fig 2B) from neonates compared with monocytes and neutrophils from adults.

TIME COURSE OF THE FMLP INDUCED DOWN REGULATION OF L-SELECTIN

Leucocytes were incubated with buffer supplemented with FMLP $10^{-12} \mathrm{M}$ at $37^{\circ} \mathrm{C}$ for $1-5$ minutes. During this incubation, surface expression of L-selectin decreased on neutrophils from both adults and neonates but the decrease was significantly $(p<0.05-p<0.001)$ less pronounced on neonates after 2-5 minutes of incubation (fig 3B). Even if neonatal neutrophils expressed less L-selectin when kept at $4^{\circ} \mathrm{C}$ compared with adults, surface expression after five minutes incubation with FMLP $\left(10^{-12} \mathrm{M}\right)$ at $37^{\circ} \mathrm{C}$ was significantly $(\mathrm{p}<0.05)$ higher on neonatal neutrophils $(8.8(1 \cdot 7) v 6.4$ (3.3) mean fluorescence intensity). On monocytes, the down regulation was less pronounced compared with neutrophils and did not differ between neonates and adults (fig 3A).

COMPARISON OF MAC-1 AND L-SELECTIN EXPRESSION FROM NEONATES DELIVERED VAGINALLY VERSUS NEONATES DELIVERED BY CAESAREAN SECTION

Samples from six neonates delivered by caesarean section were compared with samples drawn from six neonates vaginally delivered to 

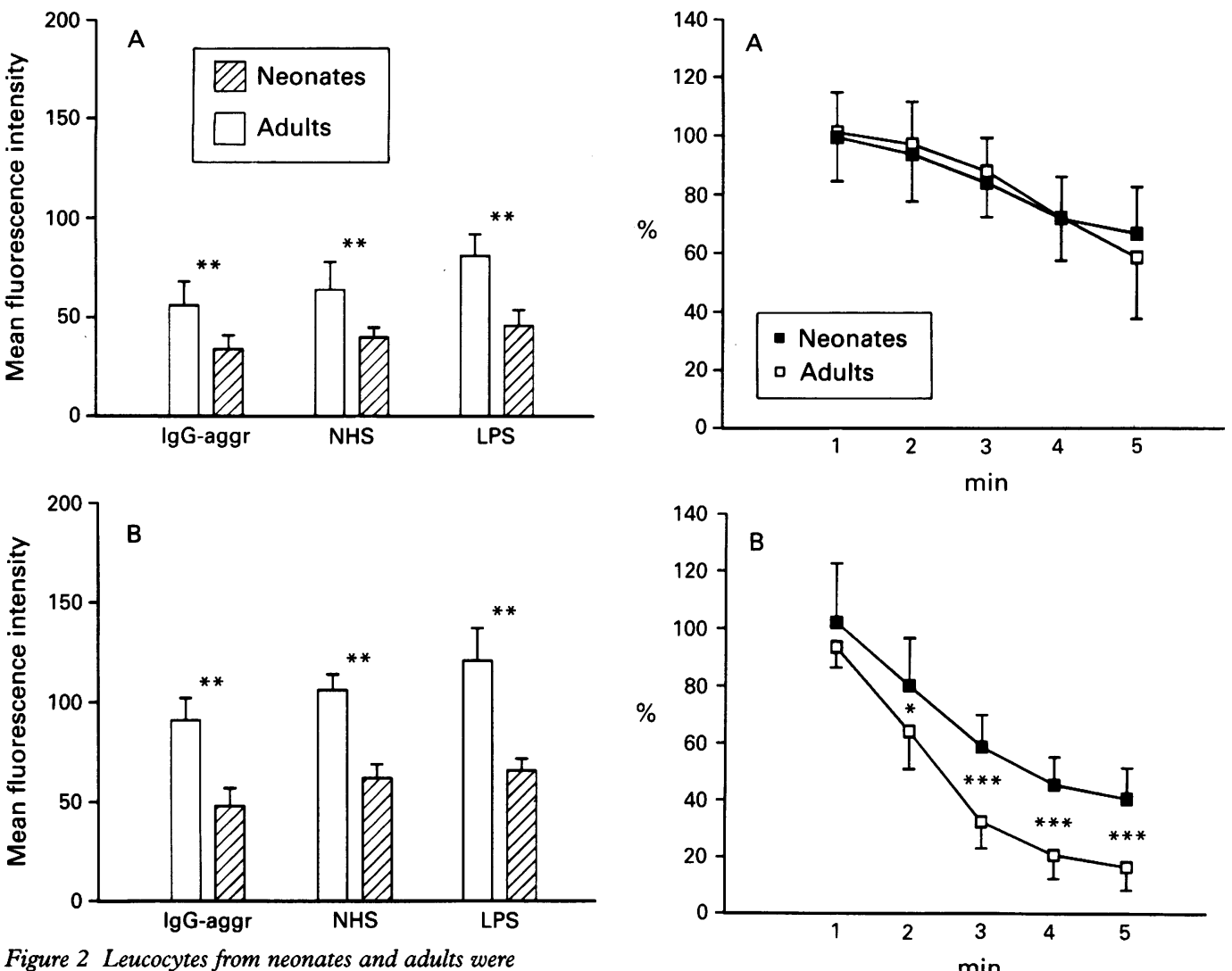

Figure 2 Leucocytes from neonates and adults were incubated with aggregated IgG (IgG-aggr) $(2.5 \mathrm{mg} / \mathrm{ml})$, $10 \%$ activated normal human serum (NHS) and lipopolysaccharides (LPS) $(100 \mu \mathrm{g} / \mathrm{ml})$ at $37^{\circ} \mathrm{C}$ for 15 minutes and were then analysed according to surface expression of Mac-1. The monocyte $(A)$ and neutrophil (B) populations were gated and analysed by flow cytometry. Results are expressed as mean (SD) and are based on six experiments; $\star \star=p<0.01$.

evaluate the influence of mode of delivery for expression of Mac-1 and L-selectin. The expression of Mac-1 on monocytes and neutrophils kept at $4^{\circ} \mathrm{C}$ and after stimulation with FMLP $\left(10^{-7} \mathrm{M}\right)$ at $37^{\circ} \mathrm{C}$ for 15 minutes did not significantly $(p>0.8)$ differ between the two groups. Additionally, surface expression on monocytes and neutrophils kept at $4^{\circ} \mathrm{C}$ and the FMLP $\left(10^{-12} \mathrm{M}\right)$ induced down regulation of L-selectin were not significantly $(p>0.8)$ influenced by mode of delivery in our subjects (data not shown).

\section{Discussion}

Recruitment of inflammatory cells is a key event in host defence against microbes and involves adhesion to and migration through the endothelium of the circulating inflammatory cells. ${ }^{15-17}$ Neutrophils appear within hours after onset of inflammation followed by monocytes and lymphocytes which accumulate after 6-8 hours. ${ }^{19}$ The mechanisms for this sequential accumulation are not fully known but differences in expression and regulation of adhesion molecules is probably of importance.

In this study we demonstrate a dose and time related impaired mobilisation of Mac-1 on neonatal monocytes compared with adults after incubation with the chemotactic factor FMLP. This impaired mobilisation was obtained also after stimulation with other factors related to bacterial infections such as

Figure 3 Leucocytes from neonates and adults were incubated with buffer supplemented with FMLP $\left(10^{-12} \mathrm{M}\right)$ at $37^{\circ} \mathrm{C}$ for 1-5 minutes and then analysed according to surface expression of $L$-selectin. The monocyte $(A)$ and neutrophil $(B)$ populations were gated and analysed by flow cytometry. Results are expressed as percent surface expression compared with surface expression of unstimulated (kept at $4^{\circ} \mathrm{C}$ ) cells. Results are expressed as mean (SD) and are based on seven experiments; $\star=p<0.05,{ }^{*} *=p<0.001$.

lipopolysaccharides, aggregated IgG and C5a, indicating a stimuli independent phenomenon. Neutrophils from neonates showed an impaired Mac-1 mobilisation which confirms other studies demonstrating a impaired Mac-1 mobilisation on neonatal neutrophils compared with adults after stimulation with FMLP and $\mathrm{C} 5 \mathrm{a},{ }^{27-29}$ despite a quantitative similar pool of Mac- 1.30

It is not clear whether impaired Mac-1 expression accounts for the predisposition to infection in neonates as heterozygotes for congenital deficiency of Mac-1 have no increased susceptibility to infections ${ }^{31}$; furthermore only a minor part of the total pool of Mac-1 is sufficient for binding and uptake of C3bi coated particles. ${ }^{32}$

We did not find any differences in the expression and down regulation of L-selectin on monocytes between neonates and adults. This resemblance to adults suggests that the recruitment of monocytes is less affected in neonates as it has been proposed that Lselectin mediates a major part of monocyte adhesion to activated endothelium under nonstatic conditions. ${ }^{33}$

We observed a decreased surface expression of L-selectin on neonatal neutrophils and an impaired down regulation upon stimulation with low concentrations of FMLP. On neutrophils, the surface level of L-selectin seems to be 
related to the adhesion properties to endothelium under conditions of sheer stress, ${ }^{34}$ during which CD18 dependent adhesion is reduced. ${ }^{35}$ The reduced surface level of $\mathrm{L}$ selectin may contribute to the impaired CD18 independent adhesion of neonatal neutrophils to endothelium, as discussed by others. ${ }^{36}$

In our studies, we did not find any influence of mode of delivery on Mac-1 and L-selectin regulation, confirming other studies on Mac-1 regulation. ${ }^{28} 37$ We have demonstrated diversity in the inverse regulation of Mac-1 and Lselectin on both monocytes and neutrophils in neonates. This may reflect 'immaturity' in neonatal monocytes and neutrophils, which together with 'immaturity' in other defence systems probably contribute to the increased susceptibility to infections. This study was supported by grants from the Swedish Medical
Research Council, the Swedish Work Environment Foundation, Th Berg Foundation, and Karolinska Institute.

1 Wilson CB. Immunological basis for increased susceptibility of the neonate to infection. 7 Pediatr $1986 ; 108: 1-12$.

2 Mease AD. Tissue neutropenia: the newborn neutrophil in perspective. $\mathcal{F}$ Perinatal 1990 ; x: 55-9.

3 Christensen RD, MacFarlane JL, Taylor NL, Hill HR. Blood and marrow neutrophils during experimental group $B$ streptococcal infection: quantification of the stem cell, proliferative, storage and circulating pools. Pediatr Res 1982; 16: 549-53.

4 Erdman SH, Christensen RD, Bradley PP, Rothstein G. Supply and release of storage neutrophils: a developmental study. Biol Neonate 1982; 41: 132-7.

5 Anderson DC, Hughes B, Smith CW. Abnormal motility of neonatal polymorphonuclear leukocytes. F Clin Invest 1981; 68: 863-74.

6 Anderson DC, Rothlein R, Marlin SD, Krater SS, Smith $\mathrm{CW}$. Impaired transendothelial migration by neonatal neutrophils: abnormalities of Mac-1 (CD1 1 b/CD18) dependent adherence reactions. Blood 1990; 76: 2613-31.

7 Hill HR. Biochemical, structural and functional abnormalities of polymorphonuclear leukocytes in the neonate. Pediatr Res 1987; 22: 375-85.

8 Miller ME. Chemotactic function in the human neonate humoral and cellular aspects. Pediatr Res 1971; 5: 487-92

9 Quie PG. Antimicrobial defenses in the neonate. Semin Perinatol 1990; 14: 2-9.

10 Miller ME. Phagocytosis in the newborn infant: humoral and cellular factors. F Pediatr 1969; 74: 255-9.

11 van Furth R, Diesselhoff den Dulk MMC, Mattie H. Quantitative study on the production and kinetics of mononuclear phagocytes during an acute inflammatory reaction. $\mathcal{F}$ Exp Med 1973; 138: 1314-30.

12 Haslett C, Henson PM Resolution of inflammation. The molecular and cellular biology of wound repair. New York: Plenum, 1988; 7: 185-211.

13 Wahl SM. Acute and chronic inflammation. In: Zembala $\mathrm{M}$, Asherson GL, eds. Human monocytes San Diego: Academic Press, 1988.

14 Stein $M$, Keshav $S$. The versatility of macrophages. Clin Exp Allergy 1992; 22: 19-27.

15 Arnaout A. Structure and function of the leukocyte adhesion molecules CD11/CD18. Blood 1990; 75: 1037-50.

16 Carlos TM, Harlan JM. Membrane proteins involved in phagocyte adherence to endothelium. Immunol Rev 1990; 114: 5-28.

17 Springer TA. Adhesion receptors of the immune system. Nature 1990; 346: 425-34.
18 von Andrian UH, Chambers JD, McEvoy LM, Bargatze RF, Arfors KE, Butcher EC. Two-step model of leukocyte-endothelial cell interaction in inflammation: distinct roles for LECAM-1 and the leukocyte beta-2 integrins in vivo. Proc Natl Acad Sci USA 1991; 88: 7538-42.

19 Hogg N. Roll, roll roll your leukocyte gently down the vein. Immunol Today 1992; 13: 113-5.

20 Zimmerman GA, Prescott SM, McIntyre TM. Endothelial cell interactions with granulocytes: tethering and signaling molecules. Immunol Today 1992; 13: 93-9.

21 Jutila MA, Rott L, Berg EL, Butcher EC. Function and regulation of the neutrophil MEL-14 antigen in vivo: comparison with LFA-1 and MAC-1. F Immunol 1989; 149: parison with 24.

22 Kishimoto TK, Jutila MA, Berg EL, Butcher EC. Neutrophil Mac-1 and MEL-14 adhesion proteins inversely regulated by chemotactic factors. Science 1989 ; 245: $1238-41$.

23 Hed J, Berg O, Forslid J, Halldén G, Lärka-Raffner G The expression of CR1 and CR3 on non-modulated and modulated granulocytes of healthy blood donors as measured by flow cytometry. Scand f Immunol 1988; 28: sured by

24 Lundahl J, Halldén G, Hed J, Johanson SGO. A flow cytometric method of measure the stimulated and the intracellular pool of the adhesion promoting glucoprotein Mac-1. APMIS 1991; 99: 139-46.

25 Miller LJ, Bainton DF, Borregaard N, Springer TA Stimulated mobilization of monocyte Mac-1 and p150.95 adhesion proteins from intracellular vesicular compartment to the cell surface. 7 Clin Invest 1987; 80: 535-44.

26 Wright SD, Ramos RA, Hermanowski-Vosatka A, Rockwell P, Detmers PA. Activation of the adhesive capacity of CR3 on neutrophils by endotoxin: dependence on lipopolysaccharide binding protein and CD14. $₹$ Exp Med 1991; 173: 1281-7.

27 Anderson DC, Becker Freeman KL, et al. Abnormal stimulated adherence of neonatal granulocytes: impaired induction of surface expression Mac-1 by chemotactic factors or secretagogues. Blood 1987; 70: 740-50.

28 Bruce MC, Baley JE, Medvik KA, Berger M. Impaired surface membrane expression of $\mathrm{C} 3 \mathrm{bi}$ but not $\mathrm{C} 3 \mathrm{~b}$ receptors on neonatal neutrophils. Pediatr Res 1987; 21: 306-11.

29 Smith JB, Campbell DE, Ludomirsky A, et al. Expression of the complement receptors CR1 and CR3 and the type III Fc receptor on neutrophils from newborn infants and from fetuses with Rh disease. Pediatr Res 1990; 28: $120-6$.

30 Jones DH, Schmalstieg FC, Dempsey K, et al. Subcellular distribution and mobilization of Mac-1 (CD11b/CD18) in neonatal neutrophils. Blood 1990; 75: 488-98.

31 Anderson DC, Springer TA. Leukocyte adhesion deficiency. An inherited defect in the Mac-1, LFA-1 and p150.95 glucoproteins. Annu Rev Med 1987; 38: 175-94.

32 Dana N, Todd III RF, Pitt J, Springer TA, Arnaout MA. Deficiency of a surface membrane glycoprotein (Mo 1$)$ in man. 7 Clin Invest 1984; 73: 513-9.

33 Spertini O, Luscinskas FW, Gimbrone Jr MA, Tedder TF. Monocyte attachment to activated endothelium in vitro is mediated by leukocyte adhesion molecule-1 (L-selectin) under nonstatic conditions. $f$ Exp Med 1992; 175: under nonst $1789-92$.

34 Smith CW, Kishimoto TK, Abbass O, et al. Chemotactic factors regulate lectin adhesion molecule 1 (LECAM-1)
dependent neutrophil adhesion to cytokine stimulated dependent neutrophil adhesion to cytokine stimulated
endothelial cells in vitro. $f$ Clin Invest 1991; 87: 609-18.

35 Lawrence MB, Smith CW, Eskin SG, McIntire LV. Effect of venous shear stress on CD18-mediated neutrophil adhesion to cultured endothelium. Blood 1990; 75: 227-37.

36 Anderson DC, Abbassi O, Kishimoto TK, Koenig JM, McIntire LV, Smith CW. Diminished lectin-, epidermal growth factor-, complement binding domain-cell adhesion molecule-1 on neonatal neutrophils underlies their impaired CD18-independent adhesion to endothelial cells in vitro. F Immunol 1991; 146: 3372-9.

37 Fleit HB. Fc and complement receptor (CR1 and CR3) expression on neonatal human polymorphonuclear leukocytes. Biol Neonate 1989; 55:156-63. 